\title{
Structural damages observed in state buildings after Simav/Turkey earthquake occurred on 19 May 2011
}

\author{
Y. S. Tama \\ Department of Civil Engineering, Pamukkale University, Denizli, Turkey \\ Correspondence to: Y. S. Tama (ystama@pau.edu.tr) \\ Received: 29 March 2012 - Revised: 23 June 2012 - Accepted: 17 July 2012 - Published: 27 August 2012
}

\begin{abstract}
Different levels of damages occurred in state buildings, especially in educational facilities, during the Simav earthquake $\left(M_{\mathrm{L}}=5.7\right)$ on 19 May 2011. A site survey was carried out in the area after the earthquake, where six state buildings were examined in detail. The results of the survey showed that main reasons for the formation of damages in these buildings are the use of low strength concrete, insufficient reinforcement, inappropriate detailing, and low-quality workmanship. The investigated buildings were also evaluated by P25-rapid assessment method. The method demonstrates that two of the buildings in question are in "high risk band"; the other two fall into "detailed evaluation band", and the rest are in the "low risk band". This figure also matches with the damages observed in the site survey.
\end{abstract}

\section{Introduction}

In the last two decades, devastating earthquakes occurred in Turkey causing extensive damages in state buildings, while most of these engineered buildings have regular structural systems. As a result of these earthquakes, many hospitals, schools and dormitory buildings collapsed resulting in significant numbers of causalities. Meanwhile, as the damaged buildings went out of service or completely collapsed, it was not possible to use them in relief efforts after such disasters (Sezer et al., 2003; Gur et al., 2004; Kaplan et al., 2004).

Simav is located in the Akşehir-Simav fault system (ASFS), which is a big seismogenic zone. ASFS is a normal oblique fault system with high seismicity. In this region, intensive seismic activity was observed in the last few years (see Fig. 1). In fact, major earthquakes occurred in this region in the past. These are 1928 Emet $(M=6.2)$, 1944 Şaphane $(M=6.2), 1970$ Gediz $(M=7.2)$ and 1970
Çavdarhisar ( $M=5.9$ ) earthquakes, which occurred in the instrumental period, and resulted in significant damages (Kaplan et al., 2011).

A moderate-sized earthquake occurred in Simav county of Kütahya Province, Turkey, on 19 May 2011. The earthquake caused severe structural damages mainly in the city center of Simav. Within the scope of the official post-earthquake damage assessments, 31127 independent structural units (i.e. houses, offices, depots etc.) were examined. It was identified that only 13169 of them were undamaged. Out of the damaged structures, 199 of them collapsed, 2867 of them heavily damaged, 1761 of them were moderately damaged, and 13131 of them were slightly damaged by the earthquake (Köksal et al., 2011).

This study focuses on damages that occurred in the state buildings caused by Simav earthquake. For this purpose, structural properties of these buildings were investigated. Through examination of the damages, it was aimed to identify what kind of structural problems resulted in their occurrence. Meanwhile, these buildings were also evaluated by using P25-rapid assessment tool, which was developed by using Turkish Damaged Building Inventory.

\section{Seismological issues}

On 19 May 2011, at 23:15 LT, a moderate-sized earthquake occurred in Simav county of Turkey. According to Disaster and Emergency Management Presidency of Turkey (DEMP), the epicentral coordinates of the earthquake are $39.1328^{\circ} \mathrm{N}-$ $29.0820^{\circ} \mathrm{E}$. The magnitude and depth of the earthquake, reported by DEMP, are $M_{\mathrm{L}}=5.7$ and $24.46 \mathrm{~km}$, respectively.

The maximum acceleration values of this earthquake were measured as $103.92 \mathrm{~cm} \mathrm{sn}^{-2}$ (gal) towards E-W direction by Gediz station, which is $31 \mathrm{~km}$ far from the epicenter of the 


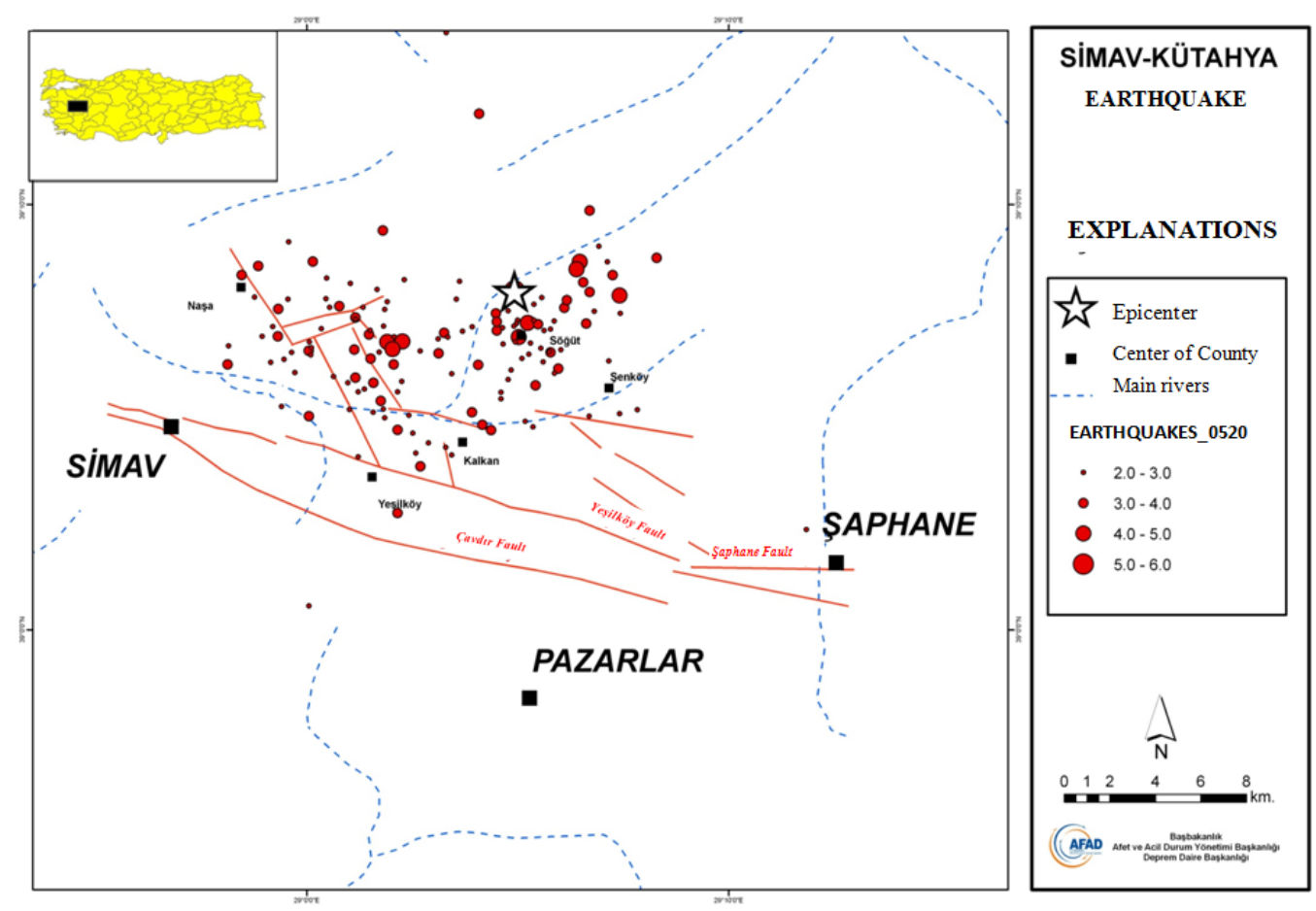

Fig. 1. Tectonics of the region and distribution of earthquake epicenters (AFAD, 2011).

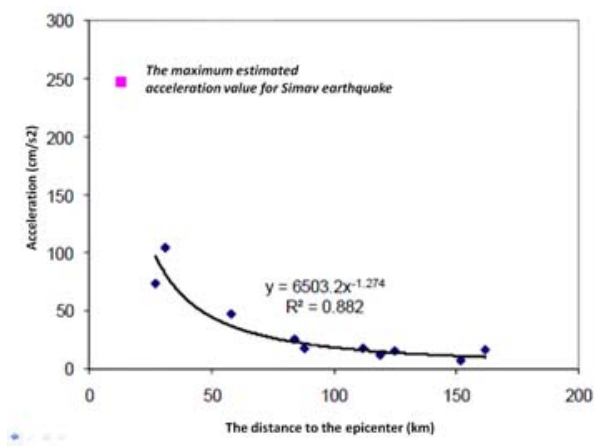

a) E-W direction

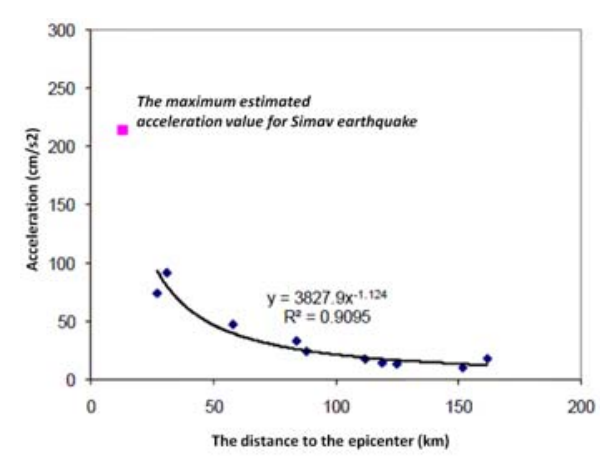

b) N-S direction

Fig. 2. Relationship between epicentral distance and maximum acceleration.

earthquake, and as $92.33 \mathrm{~cm} \mathrm{sn}^{-2}$ (gal) towards $\mathrm{N}-\mathrm{S}$ direction by the same station. Reliable measurement data were not obtained by Simav station due to its failure. Maximum acceleration values measured by different stations and the distances of these stations to the epicenter of the earthquake are given in Fig. 2. The maximum acceleration values at the city center of Simav were predicted as $214 \mathrm{~cm} \mathrm{sn}^{-2}$ (gal) towards N-S direction and $247 \mathrm{~cm} \mathrm{sn}^{-2}$ (gal) towards E-W direction (Inel et al., 2011). Acceleration values recorded at Gediz station are given in Fig. 3. Very low ground acceleration values are clearly observed for Gediz City, where no damage was reported.

\section{Properties of investigated buildings}

Within the scope of the study, six state buildings located in different regions of the Simav city center were examined: Simav Government House (SHK), 75th Year Cumhuriyet Dormitory (CLP), Cumhuriyet High School (CL), Osmanbey Primary School (OBI), Public Education Center (HEM) and Anadolu Vocational High School (AEM). General information about these buildings is given in Table 1. The buildings with different structural properties (e.g. shear walled, framed, mixed systems, heavy overhangs and with or without soft and weak storey) were selected such that they represent the 
Table 1. Basic data of investigated buildings.

\begin{tabular}{|c|c|c|c|c|c|}
\hline Building ID \& Name & Appearance & $\begin{array}{l}\text { Storey } \\
\text { Area } \\
\left(\mathrm{m}^{2}\right)\end{array}$ & $\begin{array}{l}\text { Number } \\
\text { of } \\
\text { storeys }\end{array}$ & $\begin{array}{l}\text { Construction } \\
\text { year }\end{array}$ & $\begin{array}{l}\text { Aim of } \\
\text { Use }\end{array}$ \\
\hline SHK-Simav Government House & 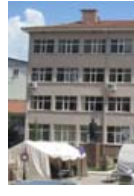 & 420 & $B+G+3$ & 1978 & Administrative \\
\hline CLP-75th Year Cumhuriyet Student Dormitory & & 625 & $B+G+3$ & 1996 & Dormitory \\
\hline CL-Cumhuriyet High School & & 675 & $\mathrm{G}+3$ & 1966 & Educational \\
\hline OBI-Osmanbey Primary School & 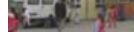 & 320 & $B+G+3$ & 1998 & Educational \\
\hline HEM-Public Education Center & & 475 & $\mathrm{G}+2$ & 1992 & $\begin{array}{l}\text { Education } \\
\text { Center }\end{array}$ \\
\hline AEM-Anatolian Vocational High School & & 430 & $\begin{array}{l}\text { G Block: } \mathrm{G}+3 \\
\text { Library: } \\
\mathrm{G}+2\end{array}$ & 1996 & Educational \\
\hline
\end{tabular}

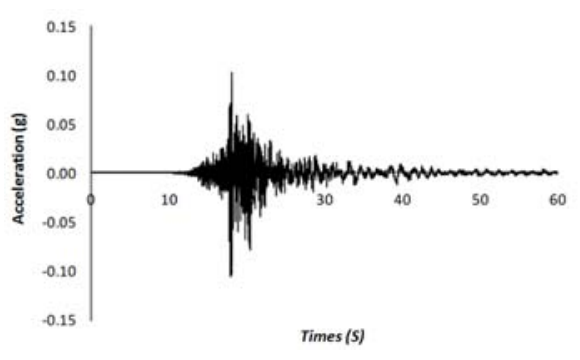

a) E-W direction

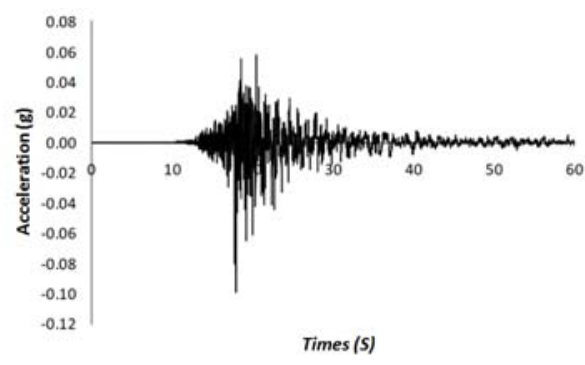

b) N-S direction

Fig. 3. Acceleration records of the Gediz station. 
Table 2. Section properties of ground floor of investigated buildings.

\begin{tabular}{|c|c|c|c|c|c|}
\hline $\begin{array}{l}\text { Building } \\
\text { ID }\end{array}$ & $\begin{array}{l}\text { Column } \\
\text { Section } \\
(\mathrm{mm})\end{array}$ & $\begin{array}{l}\text { Beam } \\
\text { Section } \\
(\mathrm{mm})\end{array}$ & $\begin{array}{l}\text { RC Shear } \\
\text { Wall } \\
\text { Thickness } \\
(\mathrm{mm})\end{array}$ & $\begin{array}{l}\text { RC Slab } \\
\text { Thickness } \\
(\mathrm{mm})\end{array}$ & $\begin{array}{l}\text { Storey } \\
\text { Height } \\
(\mathrm{mm})\end{array}$ \\
\hline SHK & $\begin{array}{l}350 / 500 \\
300 / 600 \\
400 / 500 \\
450 / 500 \\
500 / 500\end{array}$ & $250 / 600$ & 300 & 120 & 3200 \\
\hline CLP & $\begin{array}{l}400 / 1000 \\
550 / 750\end{array}$ & $\begin{array}{l}300 / 550 \\
300 / 600 \\
400 / 800\end{array}$ & 300 & 150 & 3150 \\
\hline CL & $\begin{array}{l}250 / 600 \\
600 / 350\end{array}$ & $\begin{array}{l}250 / 600 \\
600 / 350\end{array}$ & N/A & 150 & 3500 \\
\hline OBI & $\begin{array}{l}500 / 300 \\
600 / 300\end{array}$ & $300 / 600$ & 300 & 150 & 3400 \\
\hline HEM & $300 / 600$ & $300 / 600$ & 300 & 120 & 3200 \\
\hline AEM & $\begin{array}{l}300 / 800 \\
400 / 400 \\
400 / 500\end{array}$ & $400 / 750$ & N/A & 150 & 3150 \\
\hline
\end{tabular}

Table 3. Material properties and detailing.

\begin{tabular}{|c|c|c|c|c|c|c|}
\hline $\begin{array}{l}\text { Building } \\
\text { ID }\end{array}$ & $\begin{array}{l}\text { Concrete } \\
\text { Strength } \\
(\mathrm{MPa})\end{array}$ & $\begin{array}{l}\text { Steel } \\
\text { Type }\end{array}$ & Corrosion & $\begin{array}{l}\text { Hook } \\
\text { Angle } \\
\text { (Degree) }\end{array}$ & Stirrup & $\begin{array}{l}\text { Confinement } \\
\text { Zone } \\
\text { Length } \\
(\mathrm{mm})\end{array}$ \\
\hline SHK & 7.5 & $\mathrm{~S} 220$ & $\begin{array}{l}\text { Not } \\
\text { observed }\end{array}$ & $90^{\circ}$ & $\phi 8 / 200 / 120$ & 700 \\
\hline CLP & $\begin{array}{l}8.5(\mathrm{~B} \& \mathrm{G}) \\
14.5(1 \mathrm{st}) \\
7.6(2 \mathrm{nd}) \\
5.0(3 \mathrm{rd})\end{array}$ & & & & $\phi 8 / 200 / 200$ & N/A \\
\hline CL & 10.9 & & & & $\phi 6 / 200 / 200$ & N/A \\
\hline OBI & $\begin{array}{l}11.0(\mathrm{~B}) \\
9.0 \text { (Others) }\end{array}$ & & & & $\phi 8 / 200 / 120$ & 500 \\
\hline HEM & $\begin{array}{l}5.8(\mathrm{G}) \\
11.1 \text { (Others) }\end{array}$ & & & & $\phi 8 / 250 / 250$ & N/A \\
\hline AEM & 6.0 & & & & $\phi 8 / 200 / 200$ & N/A \\
\hline
\end{tabular}

stock of the state structures in Turkey. Similarly, the properties of the buildings, such as short column, end wall, the year of construction, the strength of concrete and the details of confinement, show variation in the selection. The dimensions of the structural elements in the ground floors are given in Table 2. Meanwhile, the structural plans of the buildings are shown in Fig. 4. As seen from the figure, in some of the buildings, the structural elements of the same dimensions are used throughout the storey, whereas for some others they have different dimensions in cross-section. For example, while all the beams have the same dimensions in OBI, SHK has columns of five different dimensions, and similarly CLP has beams of three different dimensions throughout the storey. Material properties and details of the confinement are given in Table 3. As it can be depicted from the table, concrete strength is extremely low for all buildings in question, and the same 


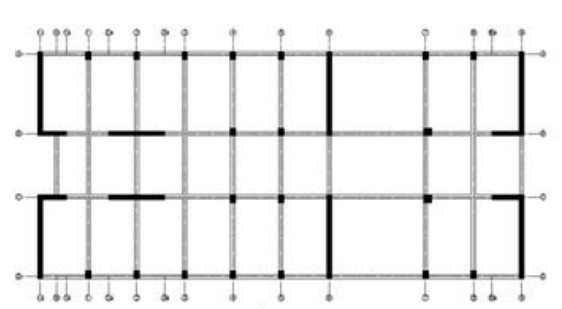

a) SHK

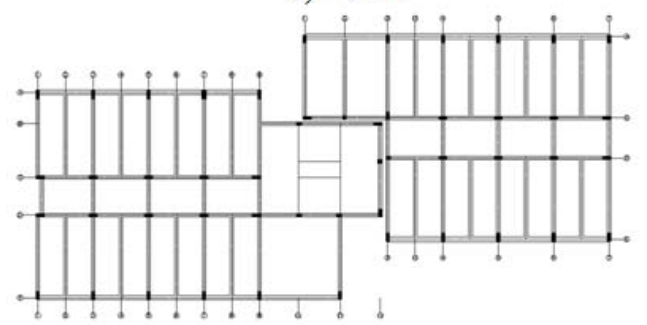

c) $\mathrm{CL}$

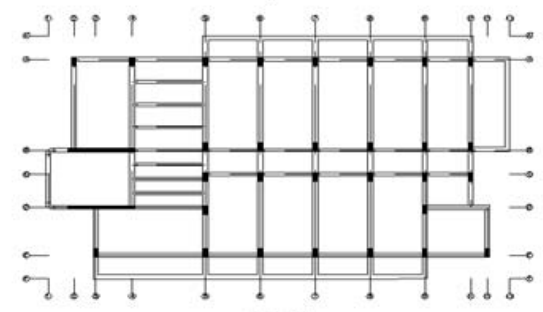

First Floor

e) $\mathrm{HEM}$

Fig. 4. Structural plan of the buildings.

type of reinforcement (i.e. S220 steel) had been used. Meanwhile, visual inspection of the damaged items demonstrates that confinement is poor at the end of the frame elements.

\section{Observed damages}

State buildings such as Government House, Governor's Office, schools and hospitals are the structures that should be used immediately after an earthquake for the purpose of administration and/or for relief efforts. Thus, these buildings should be constructed properly such that they are not damaged by an earthquake and they keep on providing service.

During the Simav earthquake, which occurred on 19 May 2011 with a magnitude of $M_{\mathrm{L}}=5.7$, severe damages that occurred in structural systems of many state buildings and as a result of this they became out of service. Within the scope of this study, the damages occurred in six state buildings were identified, which can be outlined as follows:

- In the Simav Government House (SHK), load bearing elements and infill walls were damaged (Fig. 5a). As seen from Fig. $5 b$ and c, damages in load bearing systems are sliding shear damages on the upper edges of the column and shear cracks at shear walls.

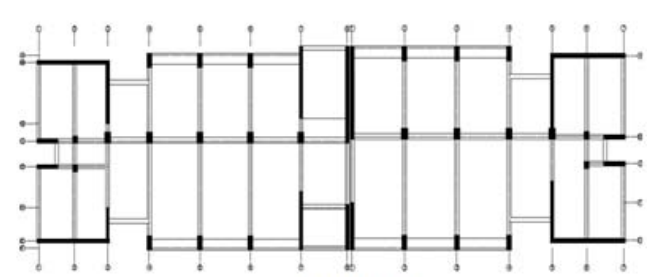

b) CLP

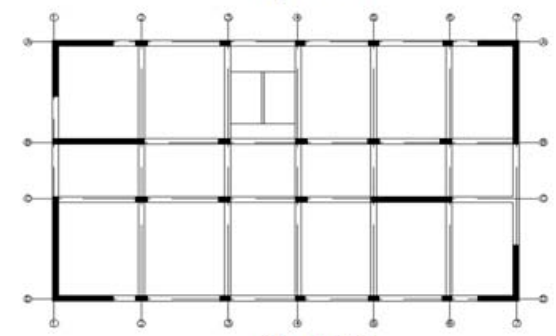

d) $\mathrm{OBI}$

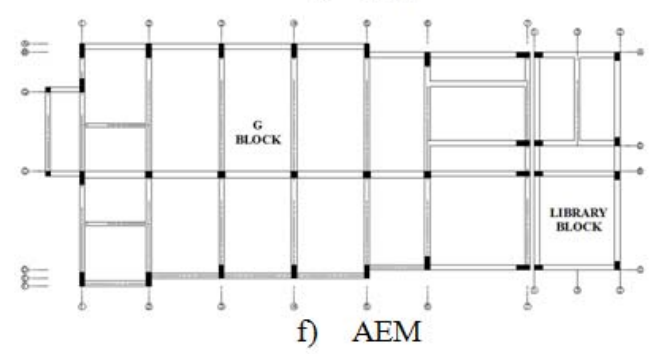

- On the ground floor of the 75th Year Cumhuriyet Dormitory (CLP), there are minor infill wall damages and separation between frame and infill walls (see Fig. 5d). Moreover, the end wall on the roof of the structure collapsed in the out-of-plane direction because of the earthquake (Fig. 5e, f). The reasons for this damage were identified as the excessive unsupported wall length and lack of horizontal and vertical bond beams at the end walls.

- In the B block of the Cumhuriyet High School (CL), shear damages occurred on the columns neighbouring the band-type windows due to short column mechanisms (Fig. 5g, h). Meanwhile, extensive infill wall damages occurred throughout the structure (Fig. 5i).

- In Osmanbey Primary School (OBI), walls crushed, plaster fell and infill wall-frame separations occurred (Fig. 5j). In some beams, cracks formed due to lap splice (Fig. 5k) and flexural forces were identified (Fig. 5l).

- In the Public Education Center (HEM), mainly infill wall damages occurred. Additionally, it was detected that there are sliding shear damages on the shear walls and columns of the ground floor (Fig. 5m, n). 


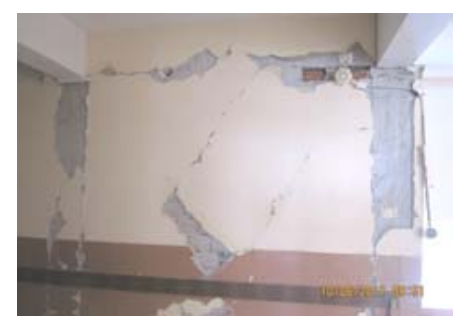

a)

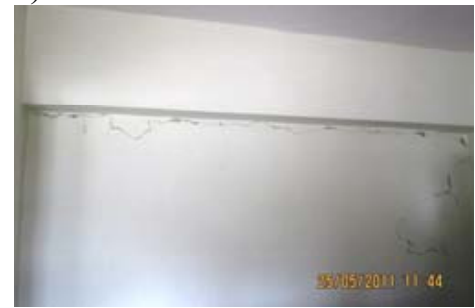

d)

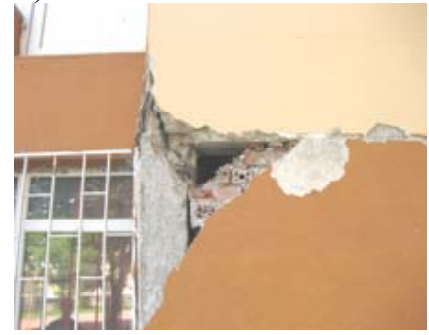

g)

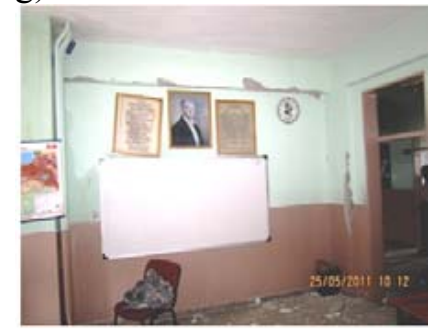

j)

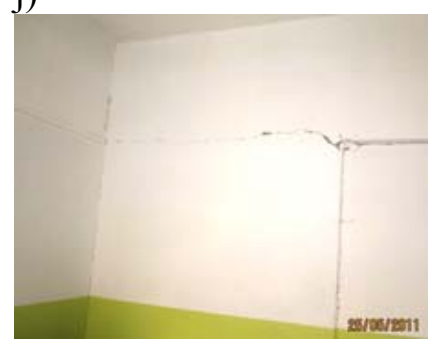

$\mathrm{m})$

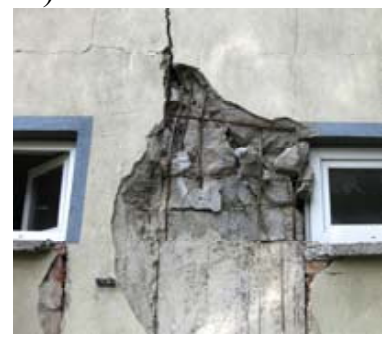

p)

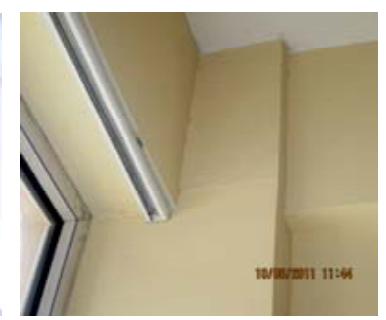

b)

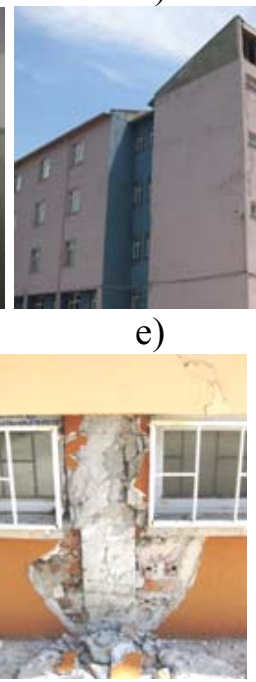

h)

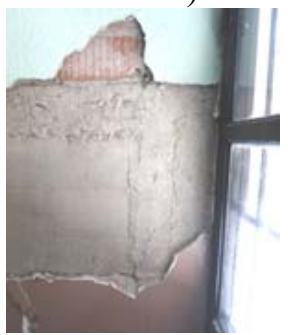

k)

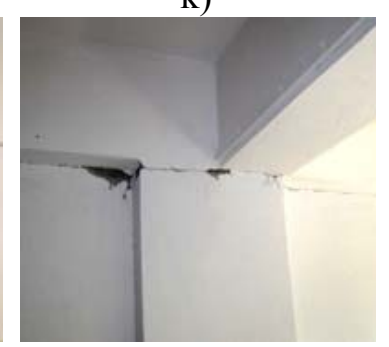

n)

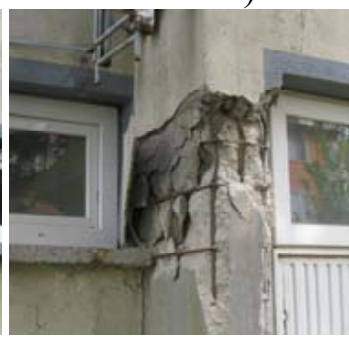

q)

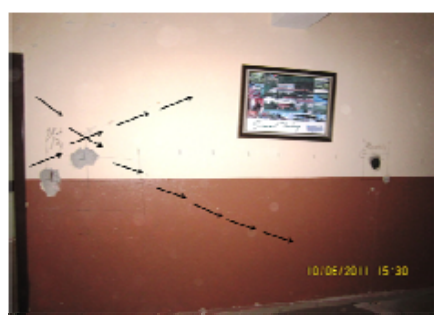

c)

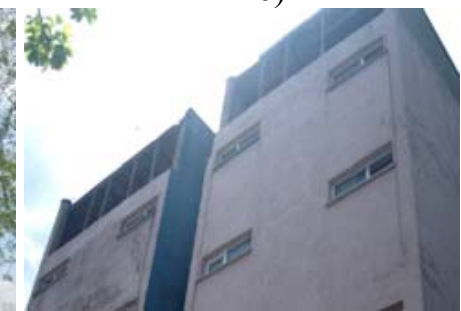

f)

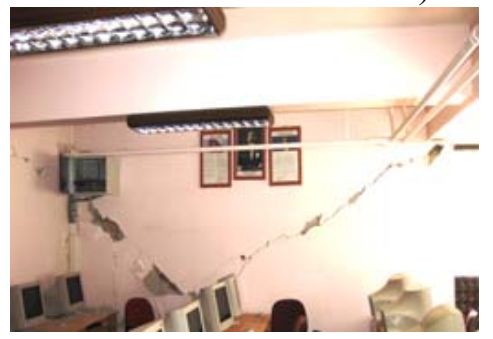

i)

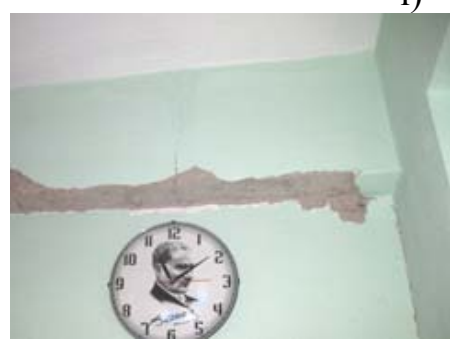

1)

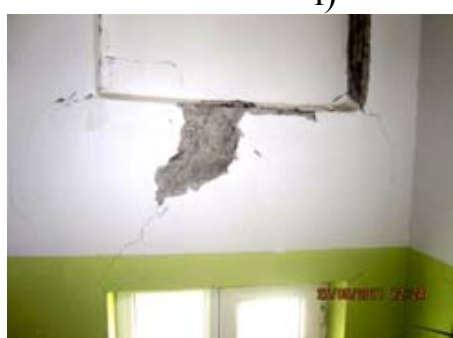

o)

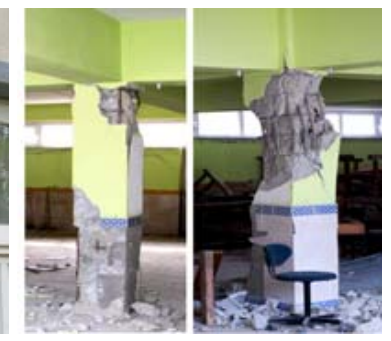

r)

Fig. 5. Observed typical damages at investigated buildings. 
Meanwhile, there are shear damages at the short beams connecting to the shear walls (Fig. 5o).

- In Anadolu Vocational High School (AEM), significant damages occurred on the infill walls and other structural members during the earthquake the occurred on 17 February 2009 with magnitude of $M_{\mathrm{L}}=5.0$ and thereby the building had been evacuated. As there were no partition walls on the ground floor, which was used as a cafeteria, "weak storey" formed and damages concentrated on this floor. In this two-block building, blocks collided with each other during the 2009 Earthquake as there was no sufficient joint length between them. As a result of this, significant damages occurred on the columns of the pounding parts of the building. In fact, these pounding damages proceeded and the concrete crushed during the recent earthquake that occurred on 19 May 2011 (see Fig. 5p). Meanwhile, due to band-type windows, the ground floor of the structure suffers from short column damages. Apart from these, during the earthquake with magnitude of $M_{\mathrm{L}}=5.0$, shear damages occurred on the short columns. In the recent earthquake, more severe damages occurred in the building such that crushing of covering concrete and buckling of the longitudinal reinforcements were observed (Fig. 5q). Meanwhile, it was detected that, in the 2009 earthquake, bending and shear damages occurred on the columns present in the central part of the ground floor. In this recent earthquake with magnitude of $M_{\mathrm{L}}=5.7$, these damages proceeded further ( shown in Fig. 5r).

For the buildings surveyed, the observed level of damages, concrete strength and the confinement of the ground floor in each building are given in Fig. 6. For a structure, it is expected that the increase in the confinement and concrete strength decreases the level of damage. However, the investigated buildings point out that such a direct relation between the level of damage and confinement, as well as the concrete strength, is not reliable. For example, it was detected that, in Cumhuriyet High School (CL), while the concrete strength is higher compared to the other structures in question, the damage is more severe. The main reasons for these problems are the presence of short columns and soft storey in this building. In contrast to Cumhuriyet High School (CL) in Public Education Center building (HEM), there is a moderate level of damage while it has the lowest concrete strength compared to the other buildings. This higher performance of the building could be attributed to presence of a regular frame structural system with no weak/soft storey. Meanwhile, higher concrete strength of the upper storeys compared to the ground storey also contributed to this result. Due to short columns and soft storey effect, Anadolu Vocational High School building (AEM), having similar concrete strength to Public Education Center (HEM), was heavily damaged during the earthquake with magnitude of $M_{\mathrm{L}}=5.7$.

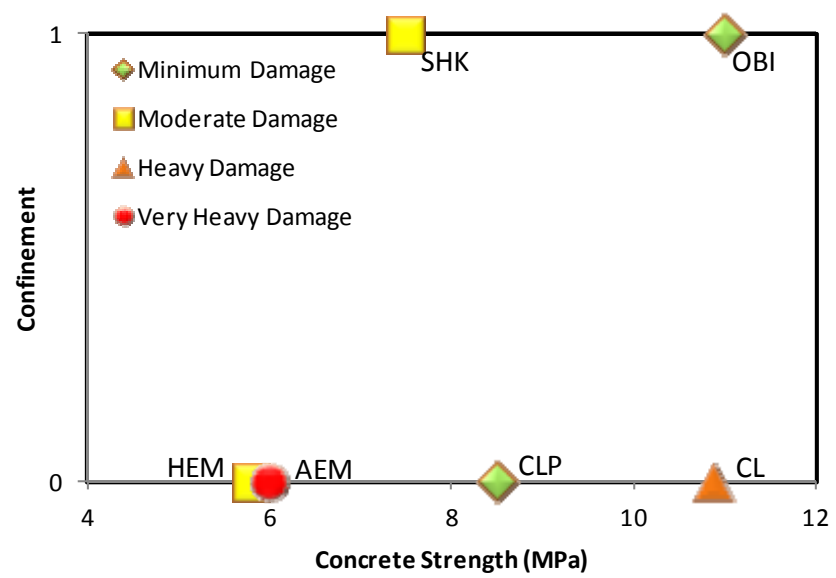

Fig. 6. Effect of concrete strength and confinement on damage level.

\section{The performance assessment of the buildings with P25 rapid assessment method}

\subsection{P25 Method}

In order to assess the seismic safety of existing buildings, they should be analyzed using either linear or nonlinear methods according to the relevant codes. However, this process is neither economical nor practical. Besides, it could be very difficult or even impossible for a huge building stock to perform such an analysis. For this reason, many rapid assessment methods that can determine the seismic risk of structures without detailed analytical studies were developed (Shiga et al., 1968; Bresler, 1977; FEMA 155, 1988; Ohkubo, 1990; NRCC, 1993; Gulkan and Sozen, 1999; Lang, 2002; Yakut, 2004; Xavier et al., 2006; Gulay et al., 2008). In order to develop such a rapid assessment method, a building stock with a specific character is mainly used and the developed method reflects the characteristics of this specified stock. Thus, when a building stock is analyzed by a rapid assessment method, it is important to use a method previously developed for a stock with similar properties. For this reason, in order to analyze the performance of the state buildings in question, P25-rating method (Gulay et al., 2008), which was recently developed for Turkish Building Stock, was used in this study.

P25-method primarily aims to determine the failure risk of the buildings rapidly so that the number of causalities in earthquakes could be minimized. The method calculates a "P-result score" for a building using 25 different parameters, such as stiffness, strength, ductility, the height of building, various structural irregularities, material quality, pounding and soil conditions, that are important for earthquake resistant design. For buildings investigated within the scope of this study, P-scores that are calculated for different structural and non-structural properties are summarized in Table 4 . The 
Table 4. Calculation of P-scores.

\begin{tabular}{lll}
\hline P-score & Explanation & Formulation \\
\hline$P_{0}$ & Structural System Score & $P_{0}=\left(C_{A}+C_{I}\right) / h_{0}$ \\
$P_{1}$ & Basic Structural Score & $P_{1}=P_{0} \cdot\left(\begin{array}{c}14 \\
\pi=1 \\
i=1\end{array}\right)$ \\
$P_{2}$ & Short Column Score & Taken from related tables in Gulay et al. (2008). \\
$P_{3}$ & Soft \& Weak Storey Score & $P_{3}=100 \cdot\left[r_{a} \cdot r_{r} \cdot\left(h_{i+1} / h_{i}\right)^{3}\right]^{0.60}$ \\
$P_{4}$ & Overhangs and Frame Irregularities Score & \\
$P_{5}$ & Pounding Score & Taken from related Tables in Gulay et al. (2008). \\
$P_{6}$ & Liquefaction Potential Score & \\
$P_{7}$ & Soil Settlement \& Displacement Score & \\
$P_{w}$ & Weighted Average Score & $P_{w}=\sum\left(w_{i} \cdot P_{i}\right) / \sum w_{i}$ \\
& & $w_{i}$ values are given in Table 5. \\
$P$ & Final Score & $P=\alpha \cdot \beta \cdot P_{\text {min }}$ \\
& & $\alpha=(1 / I) \cdot\left(1.4-A_{0}\right) \cdot[1 /(0.4 \cdot n+0.88)] \cdot t$ \\
& & $\beta$ should be taken from Fig. 7. \\
& & $P_{\text {min is the minimum of } P_{1}-P_{7} .}$
\end{tabular}

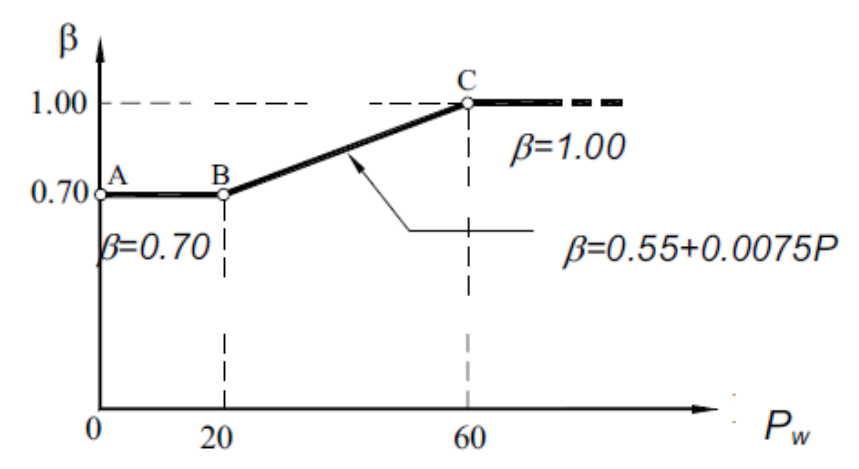

Fig. 7. $\beta$ coefficient (Gulay et al., 2008).

weighted average and final scores were also calculated for each building in which these seven scores were used.

According to the calculated $\mathrm{P}$ scores, buildings are divided into three risk groups. According to this, the buildings with $\mathrm{P}$ value less than or equal to 15 are in the "high risk band", the buildings with $P$ values in the range of 15 and 30 (i.e. 15 $<\mathrm{P} \leq 30)$ are in the "detailed evaluation band" and the buildings with $\mathrm{P}$ values higher than 30 are considered in the "low risk band".

\subsection{Results of rapid assessment}

Rapid assessment results for the buildings investigated in this study are given in Table 6. As seen from the table, AEM and HEM buildings are in the "high risk band", SHK and CL buildings in the "detailed evaluation band" and CLP and OBI
Table 5. $w_{i}$ values for $P_{i}$ scores (Gulay et al., 2008).

\begin{tabular}{lllllllll}
\hline Weighting ratio & $P_{1}$ & $P_{2}$ & $P_{3}$ & $P_{4}$ & $P_{5}$ & $P_{6}$ & $P_{7}$ & $P_{\min }$ \\
\hline$w_{i}$ & 4 & 1 & 3 & 2 & 1 & 3 & 2 & 4 \\
\hline
\end{tabular}

Table 6. P25 Scores and observed damages for buildings.

\begin{tabular}{llll}
\hline Building & P25 Score & P25 risk band & $\begin{array}{l}\text { Observed } \\
\text { damage }\end{array}$ \\
\hline OBI & 38.13 & Low Risk & Minimum \\
CLP & 37.79 & Low Risk & Minimum \\
SHK & 18.65 & Detailed Evaluation & Moderate \\
HEM & 14.93 & High Risk & Moderate \\
CL & 20.31 & Detailed Evaluation & Heavy \\
AEM & 10.83 & High Risk & Very Heavy \\
\hline
\end{tabular}

buildings in the "low risk band". These results are reasonably correlated with the observed damage levels of the buildings.

Detailed soil and concrete tests are time-consuming and expensive methods for the rapid assessment of the structures. Besides, it is known that even new buildings with good concrete quality may suffer from seismic damages due to poor detailing and geometrical irregularities (Kaplan et al., 2010). Therefore, it was also aimed in this study to assess the buildings by neglecting the affects of these parameters to see how the correlation is affected. For this purpose, firstly it was assumed that compressive strength of the concrete is $18 \mathrm{MPa}$ design strength, for all buildings. Then, soil class was assumed to be S1 (Z1 of TEC, 2007). In these assumptions, all 


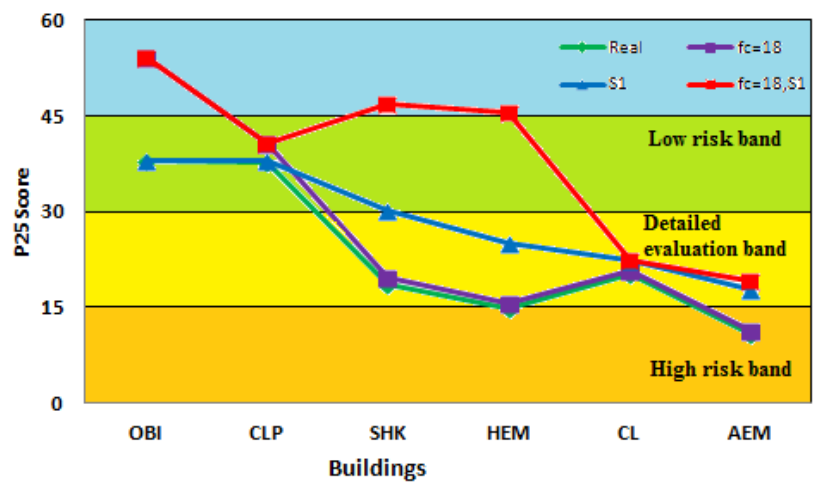

Fig. 8. Exchange of $\mathrm{P} 25$ values.

other parameters were kept constant at their values. In the last step, by using the selected concrete strength and soil type, P25 scores were re-calculated. The variations of the calculated P25 scores are given in Fig. 8.

As a result of the re-evaluation of the buildings in case of $18 \mathrm{MPa}$ concrete compressive strength, only the status of the HEM building changed from "high risk band" to "detailed evaluation band". For other buildings, there is no change in their status. In the case of S1 soil class assumption, the status of the AEM and HEM buildings changed from "high risk band" to "detailed evaluation band" and that of SHK building changed from "detailed evaluation band" to "low risk band". As the OBI building is in S2 and CLP is in S1 local ground class, the status of these buildings did not change.

Evaluation based on $18 \mathrm{MPa}$ concrete compressive strength and the local soil class assumption of S1, SHK and HEM buildings changed from "detailed evaluation band" to "low risk band". Similarly, AEM building changed from "high risk band" to "detailed evaluation band". The status of the CL building, for which short column had a significant impact on the performance of the structure, did not change.

\section{Conclusions and discussion}

On 19 May 2011, an earthquake with moderate magnitude, $M_{\mathrm{L}}=5.7$, occurred in Simav. In this study, a post-earthquake survey was conducted and six state buildings, representing the state building stock in Turkey, were examined according to the level of damages. By the investigation of these structures, the following conclusions can be drawn.

- In all of the buildings surveyed, there is no sufficient confinement at the ends of the columns, and buckling deformation occurred along the lengths of the columns, which are under effect of axial and flexural loads.

- It was detected that concrete compressive strength of the investigated buildings varies between 5.0 and $14.5 \mathrm{MPa}$.
- There are shear damages on columns neighbouring the band-type windows because of the short column mechanisms.

- There are only infill wall damages in the buildings having well-positioned shear walls. In the others, it was detected that brittle structural damages occurred extensively.

- The collapses that occurred at the end walls show that such walls must be secured against out-of-plane motion.

- It was detected that some damages occurred by pounding of the adjacent buildings, as a sufficient gap was not left between them. In such buildings, sufficient gaps should certainly be left between the buildings.

Investigated buildings were also evaluated with the P25 rapid assessment method, which is the most recent method developed for Turkish Building Stock. The results of the evaluation are as follows:

- HEM and AEM buildings are in "high risk" band, CL and SHK buildings in "detailed evaluation" band, CLP and OBI buildings in the "low risk" band. The observed levels of damage that occurred in these buildings were found to be correlated with the results of P25 rapid assessment.

- The method also gives reasonable results for the assumption of the constant concrete strength, which allows less material characterization workload. However, assuming a standard soil type without detailed site investigations brings a significant amount of deviation to the results. It can be stated that P25-method can be used for rapid evaluation of the existing buildings.

Acknowledgements. Author acknowledges Hasan Kaplan, Salih Yilmaz, Hayri Un, Erdal Akyol and Ahmet Sarisin for their valuable comments and help during site investigations.

Edited by: O. Katz

Reviewed by: two anonymous referees

\section{References}

AFAD-Republic of Turkey Prime Ministry Disaster and Emergency Management Presidency, http://www.deprem.gov.tr, 2011.

Bresler, B.: Evaluation of Earthquake Safety of Existing Buildings, Developing Methodologies for Evaluating the Earthquake Safety of Existing Buildings, Earthquake Engineering and Research Center Univ. of California, UCB/EERC-77/06, Berkeley, 157 pp., 1977.

FEMA 155-ATC-21-1: Rapid Visual Screening of Buildings for Potential Seismic Hazards:Supporting Documentation, Applied Technology Council, Federal Emergency Management Agency, Washington DC, 1988. 
Gulay, F. G., Bal, Ý. E., and Tezcan, S. S.: Calibration of the P25 Scoring Method developed for the seismic safety of reinforced concrete buildings and its application on a pilot region. TÜBITAK (Turkish Scientific and Technical Research Council) Research Project No 106M278, Final Report, 2008 (in Turkish).

Gulkan, P. and Sozen, M. A.: Procedure for Determining Seismic Vulnerability of Building Structures, ACI Structural Journal, 96, 3, 336-342, 1999.

Gur, T., Ramizez, J. A., and Sozen, M.: Performance of school buildings in Bingol during the 1st May 2003 earthquake, 8, 2. Earthquake Hazard Center, 1-20, 2004.

Inel, M., Ozmen, H. B., Akyol, E., and Caycı, B. T.: 19 May 2011 Kütahya- Simav earthquake and aftershocks review report, TMMOB Denizli Branch of Chamber of Civil Engineers, 1-37, May, 2011.

Kaplan, H., Yilmaz, S., Binici, H., Yazar, E., and Cetinkaya, N.: May 1, 2003 Turkey-Bingol earthquake: damage in reinforced concrete structures, Eng. Fail. Anal., 11, 279-291, 2004.

Kaplan, H., Bilgin, H., Yilmaz, S., Binici, H., and Öztas, A.: Structural damages of L'Aquila (Italy) earthquake, Nat. Hazards Earth Syst. Sci., 10, 499-507, doi:10.5194/nhess-10-499-2010, 2010.

Kaplan, H., Tama, Y. S., Yilmaz, S., Kayhan, A. H., and Un, H.: Preliminary Investigation Report of Structural Damages of 19 May 2011 Simav Earthquake, Pamukkale University, 25 May 2011.

Köksal, T. S., Avşar, O., and Yilmaz, N.: Reasons of structural damages occurred during 19 May 2011 Kütahya-Simav earthquake, 1st Turkey Earthquake Engineering and Seismology Conference, METU, 11-14 October 2011.
Lang, K.: Seismic vulnerability of existing buildings, (PhD dissertation), Eidgenoessische Technische Hochschule Zuerich, Switzerland, 2002.

NRCC: Manual for Screening of Buildings for Seismic Investigation, National Research Council of Canada, Ottawa, 1993.

Ohkubo, M.: The Method for Evaluating Seismic Performance of Existing Reinforced Concrete Buildings, Seminar in Structural Engineering, Dept. of AMES, University of California, San Diego, 1990.

Sezer, H., Whittaker, A. S., Elwood, K. J., and Mosalam, K. M.: Performance of reinforced concrete buildings during the August 17, 1999 Kocaeli, Turkey earthquake, and seismic design and construction practise in Turkey, Eng. Struct. J., 25, 103-114, 2003.

Shiga, T., Shibata, A., and Takahashi, T.: Earthquake Damage and Wall Index of Reinforced Concrete Buildings, Proceedings, Tohuku District Symposium, Architectural Institute of Japan, 12, 29-32, 1968.

TEC-Turkish Eartquake Code: Regulations on buildings to be constructed in seismic zones, Ankara: Ministry of Public Works and Settlement, 2007.

Xavier, R., Guedes, J., Costa, A., and Delgado, R.: Seismic Risk Assessment of Reinforced Concrete Structures, First European Conference on Earthquake Engineering and Seismology, 13ECEES, Geneva-Switzerland, 882, 3-8 September 2006.

Yakut, A.: Preliminary Seismic Performance Assessment Procedure For Existing Reinforced Concrete Buildings, Eng. Struct., 26, 1447-1461, 2004. 